\title{
Experiences of father carers of children with Autism Spectrum Disorder: An exploratory study
}

\author{
Antoinette Pottas \& Athena Pedro
}

\begin{abstract}
This study aimed to explore the carer experiences of fathers of children with Autism Spectrum Disorder (ASD). A total of eight South African fathers between the ages of 38 and 45 years were the interview informants. They cared for at least one child with ASD each and their children with ASD were within the age range of five to nine years $(n=9$, males=7, females=2, Low functioning=4, Moderately functioning=4, High functioning=1).The father carers completed a semi-structured interview. The data were analysed thematically. Four primary themes emerged from the analysis pertaining to aspects of rescoping their futures to include the care of a child with ASD, relationship issues, access to and management of resources, information and support, and carer compassion and satisfaction. The fathers shared a view that caring for their children with ASD was both stimulating and enriching, and that with time, they were able to adapt, and better respond, to the specific needs of their child.
\end{abstract}

\section{Introduction}

Autism Spectrum Disorder (ASD) refers to 'a group of neurodevelopmental syndromes characterized by a wide range of impairments in social communication and restricted and repetitive behaviours' (Kaplan \& Sadock, 2015, p. 1152). It has a prevalence rate of 1 in 86 children (Centre for Disease Control and Prevention, 2014). Individuals diagnosed with ASD have impairment on a continuum from high functioning, with the low functioning requiring more intensive support and other care interventions (American Psychiatric Association, 2013; Kaplan \& Sadock, 2015). ASD is associated with severe barriers to learning and development right from the onset. Thus, carers have to content with their child's behavioural difficulties which may come with their being stigmatised and socially isolated by others in the community. Furthermore, parent carers of children with ASD may lack information regarding grants, support services and available educational options for their child, to name a few (Ludlow, Skelly, \& Rohleder, 2011). They also may lack time and energy to spend with their other children, given the fact that the child with ASD, if low functioning, may require intensive care and support (Ludlow et al., 2011).

There are comparatively more studies on the carer- parent experiences of mothers of children with ASD compared to those on father carers of children with ASD (Kourkoutas, Langher, Caldin, \& Fountoulaki, 2012; Pisula, 2011). The carer experiences by gender are 
not clear in regard to levels of stress and/or satisfaction, with some studies stating that fathers generally experience less stress than mothers, others argue that fathers experience different types of stress, and some are of the opinion that there are no significant differences between the experiences of mothers and fathers (Ludlow et al., 2011; Pisula, 2011). Naseef and Freedman (2012) postulated that mothers and fathers seem to differ with regard to the scope of their carer role and the relationship expectations around that role, with fathers preferring more of a problem-solving orientation than a nurturing one.

This study sought to explore the experiences of father carers of children with ASD in South Africa, a country with strong disability support policy instruments, and also one in which child care is typically by mothers. The study was guided by the following question: What are the experiences of fathers who provide care to their children with ASD? Findings could help individuals and organisations involved in providing support to carer fathers of children with disabilities.

\section{Method}

\section{Research design}

The qualitative approach allowed for the exploration of father carer experiences from their own perspectives. Exploratory studies are used when the topic or phenomenon to be studied is new and when data is difficult to collect (Babbie \& Mouton, 2001). This study employed an exploratory qualitative research design to characterise carer experiences of fathers of children with ASD through their own words.

\section{Procedure}

The study was approved by the Research Ethics Committee at the University of Western Cape and the Western Cape Education Department. The principals of the schools which the children attended consented to the study as did the father carers. The father carers were informed that the interview sessions were audiotaped and that they could do so without incurring any negative consequences on their part.

Table 1: Brief demographic profile

\begin{tabular}{lccccc}
\hline Participants & Father's age & Gender of child & Child's level of functioning & Marital status of father & Main caregiver \\
\hline Participant 1 & 45 & Male & Low & Widower & Father \\
Participant 2 & 40 & Male & Moderate & Married & Father \\
Participant 3 & 40 & Male & Moderate & Married & Mother \\
Participant 4 & 43 & Male & Low & Married & Mother \\
Participant 5 & 38 & Male & Moderate & Married & Father \\
Participant 6 & 40 & Male & High & Married & Shared \\
Participant 7 & 45 & Female & Low & Divorced & Shared \\
Participant 8 & 43 & Female & Mow & Married & Mother \\
\hline
\end{tabular}

\section{Participants and setting}

A convenience sample of eight fathers who were carers of their children with ASD were participants (age range 38 to 45 years) (see Table 1 for participant demographics). A total of six fathers were raising boys, with one father having two sons both on the autism 
spectrum and two had daughters diagnosed with ASD. Six of the eight fathers were married. Three of the fathers were the primary caregivers to their child with ASD.

\section{Data collection}

The father carers completed in-depth interviews on their emotional reactions to the diagnosis, effect of care on their interpersonal relationships within the family, available resources for care, and carer satisfaction. To ensure accuracy of data captured, sessions were audiotaped and transcribed verbatim. The transcriptions were also continuously checked against the audio recordings in the process of coding and cross-checking of codes for accuracy or trustworthiness.

\section{Data analysis}

Data were thematically analysed using the six-phase approach of Braun and Clark (2006) as follows: becoming familiar with the contents of the transcribed interviews; generating initial codes based on emerging aspects of interest and of meaning to the topic being studied; reviewing and refining the themes; defining and naming the themes; and concluding the analysis. To ensure confidentiality, the participating fathers' names are not included in the reporting of the results.

\section{Results and discussion}

Four themes emerged related to reframing the future, relationship qualities with spouses and other children in the family, carer resource demands and needs, and compassion and satisfaction. These themes are discussed next. We utilise acronyms to describe the child's level of functioning as follows: HF - high functioning, LF- low functioning, and MFmoderately functioning.

\section{Theme 1: Reframing the future}

All eight father carers reported initially having difficulty to come fully to grips with and understand the impact of the diagnosis, as well as perceiving a shift in their future expectations for themselves as carers of their child with ASD, and also of the likely future of their children.

Well...he's not going to be a normal child and who's going to look after him when you're not around anymore? [Participant 1, 45 years, LF boy child].

...I think as a parent, as a male, you've got high expectations you know, you see a completely bright future for your child you know, and I think initially it's probably the biggest shock that you have, which is realising that actually might not happen... [Participant 3, 40 years, MF boy child].

Similar to findings by Sicile-Kira (2003) and Romaniec (2010), the emotions most fathers mentioned when discussing the events surrounding the diagnosis was comparable to that of Kubler-Ross' five stages of grief. Particularly, fathers seemed to be concerned with the practical implications for the future, such as who will take over the care of the child when they are no longer able to, as well as how to go about securing a future for the child. 


\section{Theme 2: Relationship issues}

Six of the eight father carers perceived their carer role to add strain to their marriage and relationship with their spouse from time to time.

So yes you're gonna have your down days where your marriage is suffering and takes a hell of a knock, then of course there is those days where everything just gels together and we can work together as a team...[Participant 8, 43 years, MF girl child].

This was particularly relevant with regard to differing childcare and discipline approaches and finding time for each other as a couple. However, they felt that for the larger part their wives were a source of support and that they could work together as a team to take care of daily childcare needs.

Six of the eight fathers also mentioned that at times they experienced the majority of their time is taken up by caregiver responsibilities for their child with ASD.

You see my time mostly is occupied with him, it creates a little jealousy amongst them [Participant 5, 38 years, MF boy child].

Fathers believed to want to provide as equal time as possible to all their children. Some of the fathers also reported that their other children were quite understanding of the particular circumstances and connected well with their brother or sister with ASD regardless of the extra time differences.

In particular, fathers spoke about siblings actively engaging in the education and care of their sibling, which eased their burden of care somewhat:

I find this very useful to have the two of them, one younger and one older, and she in the middle so she can learn from both sides of the fence because the other one is going to crèche and what they teach them at crèche she actually helps the other one develop a little bit more [Participant 8, 43 years, MF girl child].

\section{Theme 3: Carer resource demands and needs}

Most of the father carers reported to experience time-demand constraints from their carer roles.

The problem with autistic children is they don't give you time to settle down, that is a problem you see. When he is at school, we have time for ourselves, I have time to go to work, do house work and all of that [Participant 1, 45 years, LF boy child].

Five fathers felt that time and care demands appeared to ease somewhat as the child got older, due to children's improved behaviour, independence and comprehension: 
...as he's growing, he's becoming more obedient, he understands what you're asking him, he can follow instructions clearly [Participant 4, 43 years, LF boy child].

Even then, fathers reported that the need to be watchful remained as some of the children with ASD tend to engage in dangerous play activities that could lead to serious injury:

...one day, I was holding both of them and got to the beach, the one went this way and the other one went that way. My concern is where are you going? You're going towards the water, you're going into the sand, fine you're safe, I can get to you now but you're going towards the water, I need to get to you first [Participant 6, 40 years, HF \& LF boy children].

Consistent with Gray (2006), fathers highlighted the fact that childcare needs change with the age of the child. They observed that each age brought with it its own set of challenges and improvements.

Four fathers also spoke of family and friends helping with childcare and providing them some respite:

So if you have parents that are around or a brother or a sister that sort of can take the child for a night or a day, whatever the case may be, it makes a big difference because it helps you with a little bit of sanity [Participant 3, 40 years, MF boy child].

However, three fathers felt that their family and friends did not provide much of a support system due to lacking knowledge and understanding of their child's specific needs:

I don't particularly like to leave her with family, because I don't think they're particularly equipped, physically and otherwise, to handle her [Participant 7, 45 years, LF girl child].

Furthermore, five fathers perceived their child's school and educators as an invaluable source of support:

...but since he's attended this school they've been wonderful to him. He can write his name, he can write his surname, all the things like that, so ja he's improved a lot at the school [Participant 5, 38 years, MF boy child].

Two fathers also made mention of how they use the internet as a source of quickly accessible information as well as support in the form of online ASD forums where they can connect and share information with other parents in similar situations:

Through her Facebook group 'Ask me I'm autistic' you learn a lot, you really do. If you want to learn more about real life autism, you go there and you join the group [Participant 7, 45 years, LF girl child]. 
Findings are consistent with Jung's (2010) view that fathers made valued formal and informal support structures in carer roles. In particular, fathers valued the contributions of their child's school as they felt it played an important role in helping their child gain improved skills, which in turn made childcare somewhat easier, as well as offering them a form of respite.

Nonetheless, fathers on a whole felt that the larger society still does not have the required awareness, knowledge or compassion with regard to children presenting with ASD:

I mean from a society perspective I just think people becoming more aware, and sort of understanding that if you're in a shopping centre and you're witnessing a child having a meltdown it's not necessarily a naughty child. So I would say from society's perspective it's definitely something, that people should become more aware [Participant 2, 40 years, MF boy child].

\section{Theme 4: Carer compassion and satisfaction}

Five fathers expressed a need and willingness to connect with other fathers in an informal manner to learn from each other and support one another:

You know like an informal gathering and saying guys, that is we have an informal gathering at the school, you are welcome and this is the day we're planning to have an evening out...Just a gap evening, so you say come have a braai and let's talk, nothing formal [Participant 6, 40 years, HF \& LF boy children].

All eight fathers reported to find joy in the abilities of their children and when they obtain new skills:

He enjoys music just like me; I mean being a musician I can see he's a great drummer, he's got great timing and his only 5... [Participant 2, 40 years, MF boy child].

Kayfitz, Gragg and Orr (2010) highlighted the importance of focusing on positive experiences as these play an important buffering role against everyday stressors. Fathers were eager to share examples of situations in which they had positive interactions with their child with ASD. The ability to connect and find interest in the same things seemed to be a great positive for fathers as it helped them in emotionally bonding with their child.

\section{Conclusion}

Father carers appeared to report less optimism regarding the futures of their child, however, this seemed to be somewhat linked to their child's level of functioning, with the fathers of the moderate to high functioning children expressing more optimism. They also noted significant time demands from carer roles, an aspect which seemed to be amplified especially with single parenthood. Nonetheless, the fathers shared a view that caring for their children with ASD was both stimulating and enriching. They also believed to adapt 
ways to meet the specific needs of their child. The fathers perceived to be less wellsupported in carer roles by the community and that lack of support added to their personal and relationship stress in carer roles. 


\section{References}

American Psychiatric Association (APA). (2013). Diagnostic and Statistical Manual of Mental Disorders (5th edn). Washington: APA.

Babbie, E., \& Mouton, J. (2001). The practice of social research. Cape Town: Oxford University Press.

Braun, V., \& Clarke, V. (2006). Using thematic analysis in psychology. Qualitative Research in Psychology, 3(2), 77-101. http://dx.doi.org/10.1191/1478088706qpo63oa.

Centre for Disease Control and Prevention. (2014). Autism Spectrum Disorder Data and Statistics. http://www.cdc.gov/ ncbddd/autism/data.html.

Gray, D. E. (2006). Coping over time: The parents of children with autism. Journal of Intellectual Disability Research, 5o(12), 970-976. http://dx.doi. org/10.1111/j.1365-2788.2006.00933.x.

Jung, L. (2010). Identifying families' support and other resources. In R. A. McWilliam (ed.), Working with families of young children with special needs. (pp. 9-26). New York, London: The Guilford Press.

Kaplan, B. J., \& Sadock, V. A. (2015). Autism Spectrum Disorder. In B. J. Kaplan \& V. A. Sadock (eds), Synopsis of Psychiatry (11 th edn) (pp. 1152-1168). New York: Wolters Kluwer.

Kayfitz, A. D., Gragg, M. N., \& Orr, R. (2010). Positive experiences of mothers and fathers of children with autism. Journal of Applied Research in Intellectual $D$ is abilities, 23(4), 337-343. http://dx.doi.org/10.1111/j.1468-3148.2009.00539.x.

Kourkoutas, E., Langher, V., Caldin, R., \& Fountoulaki, E. (2012). Experiences of parents of children with autism: Parenting, schooling, and social inclusion of autistic children. In K. J. Ripoll, A. L. Comunian, \& C. M. Brown (eds), Expanding Horizons . Current research on Interpersonal Acceptance (pp. 103-125). Boca Raton: Brown/Walker Press.

Ludlow, A., Skelly, C., \& Rohleder, P. (2011). Challenges faced by parents of children diagnosed with autism spectrum disorder. Journal of Health Psychology,17(5), 702-711. http://dx.doi.org/10.1177/1359105311422955.

Naseef, R. \& Freedman, B. (2012). A diagnosis of autism is not a prognosis of divorce. Autism Advocate Magazine Online, Fall, 9-12. https://scholar.google.com/

Pisula, E. (2011). Parenting stress in mothers and fathers of children with autism spectrum disorders. In M. R. Mohammadi (ed.), A Comprehensive Book on Autism Spectrum Disorders. e-book: InTech. www.intechopen.com.

Romaniec, M. (2010). After the autism diagnosis: Staying connected as a couple. https://www.tacanow.org/family-resources/after-the-autism-diagnosis-stayingconnected-as-a-couple/.

Sicile-Kira, C. (2003). Autism Spectrum Disorders: The Complete Guide. London: Vermilion. 